\title{
Photipyrones A and B, new pyrone derivatives from the plant endophytic fungus Pestalotiopsis photiniae
}

\author{
Gang Ding ${ }^{1,2}$, Yingxiang $\mathrm{Qi}^{3}$, Shuchun $\mathrm{Liu}^{4}$, Liangdong Guo ${ }^{4}$ and Xulin $\mathrm{Chen}^{5}$ \\ The Journal of Antibiotics (2012) 65, 271-273; doi:10.1038/ja.2012.14; published online 14 March 2012
}

Keywords: cytotoxicity; endophytes; OSMAC; Pestalotiopsis photiniae; photipyrones A and B; structure elucidation

In order to obtain more secondary metabolites in one single strain possessing genetic potential to produce different compounds, one easiest way is to vary the culture conditions. This approach was termed 'one strain many compounds' (OSMAC). ${ }^{1}$ As either endophytic or pathogenic fungus on living plant, the genera Pestalotiopsis spp. are prolific fungi, and our prior chemical studies of the species of this genus have led to the isolation of a variety of new/novel different bioactive compounds, ${ }^{2-15}$ which revealed that the genera Pestalotiopsis spp. possessed the biogenetic potential to produce different secondary metabolites with a broad range of bioactive effects. Photinides A-F with unique benzofuranone-derived $\gamma$-lactone skeleton have been isolated from the extract of Pestalotiopsis photiniae (L461) grown in SA media culture. ${ }^{5}$ In contrast, the crude isolate of the same fungus cultivated in rice-media culture in static condition produced two new $\delta$-lactone derivatives named photipyrones A (2) and B (3), along with four known analogues namely LL-P880 $\alpha(1),{ }^{16}$ LL-P880 $\beta \quad$ (4), ${ }^{17} \quad 1^{\prime}$-hydroxy-4-methoxy-6-pentyl-2H-pyran-2-one (5), ${ }^{18}$ and $1^{\prime}, 2^{\prime}$-dihydroxy-4-methoxy-6-pentyl-2H-pyran-2-one $(6)^{16}$ (Figure 1) completely different from photinides A-F from SA media culture. In this note, we will present the isolation, structure elucidation and bioactivities of these compounds.

The culture of $P$. photiniae was isolated from the plant Roystonea regia (H.B.K.) Cook collected from Jianfeng Mountain, Hainan Province, People's Republic of China, in April 2005. The isolate was identified by one of the authors (LG) based on morphology and sequence analysis of the ITS region of the ribosomal DNA and was assigned the accession number L461 in LG's culture collection at the Institute of Microbiology, Chinese Academy of Sciences, Beijing. The fungal strain was cultured on slants of potato dextrose agar (PDA) at $25^{\circ} \mathrm{C}$ for 10 days. The agar plugs were used to inoculate $250 \mathrm{ml}$ Erlenmeyer flasks, each containing $50 \mathrm{ml}$ of media ( $0.4 \%$ glucose, $1 \%$ malt extract and $0.4 \%$ yeast extract), and the final $\mathrm{pH}$ of the media was adjusted to 6.5 before sterilization. Flask cultures were incubated at $25^{\circ} \mathrm{C}$ on a rotary shaker at $170 \mathrm{rpm}$ for 5 days. Fermentation was carried out in four $500 \mathrm{ml}$ Fernbach flasks, each containing $75 \mathrm{~g}$ of rice. Spore inoculum was prepared by suspension in sterile, distilled $\mathrm{H}_{2} \mathrm{O}$ to give a final spore/cell suspension of $1 \times$ $10^{6} \mathrm{ml}^{-1}$. Distilled $\mathrm{H}_{2} \mathrm{O}(100 \mathrm{ml})$ was added to each flask and the contents were soaked overnight before autoclaving at $15 \mathrm{lb} \mathrm{in}^{-2}$ for $30 \mathrm{~min}$. After cooling to room temperature, each flask was inoculated with $5.0 \mathrm{ml}$ of the spore inoculum and incubated at $25^{\circ} \mathrm{C}$ for 40 days.

The fermented material was extracted with methyl ethyl ketone (MEK; $3 \times 500 \mathrm{ml}$ ), and the organic solvent was evaporated to dryness under vacuum to afford $4.9 \mathrm{~g}$ of crude extract, which was fractionated by silica-gel normal chromatography using $\mathrm{CH}_{2} \mathrm{Cl}_{2}-$ $\mathrm{MeOH}$ gradient elution. The fraction eluted with 98:2 $\mathrm{CH}_{2} \mathrm{Cl}_{2}-$ $\mathrm{CH}_{3} \mathrm{OH}$ was separated by Sephadex LH-20 column chromatography (Pharmacia, Uppsala, Sweden) eluted with $\mathrm{MeOH}$ to afford a subfraction of $80 \mathrm{mg}$. Purification of the fraction by semipreparative reversed-phase HPLC (Agilent Zorbax SB-C 18 column, Agilent Technologies Inc, Wilmington, DE, USA); $5 \mu \mathrm{m} ; 9.4 \times 250 \mathrm{~mm}$; $\left.2 \mathrm{ml} \mathrm{min}{ }^{-1}\right)$ afforded LL-P880 $\alpha\left(1 ; 2.0 \mathrm{mg}, t_{\mathrm{R}} 35.8 \mathrm{~min} ; 2.5 \mathrm{mg}\right.$, $15 \% \mathrm{MeCN}$ in $\mathrm{H}_{2} \mathrm{O}$ over $5 \mathrm{~min}, 15-100 \%$ over $100 \mathrm{~min}$ ); photipyrone A $\left(2 ; 1.0 \mathrm{mg}, t_{\mathrm{R}} 24.5 \mathrm{~min}\right.$; same gradient as in purification of 1 ); photipyrone $\mathrm{B}\left(3 ; 1.1 \mathrm{mg}, t_{\mathrm{R}} 16.7 \mathrm{~min}\right.$; same gradient as in purification of 1); LL-P880 $\beta\left(4 ; 3.0 \mathrm{mg}, t_{\mathrm{R}} 21.0 \mathrm{~min}\right.$; same gradient as in purification of 1); 1'-hydroxy-4-methoxy-6-pentyl-2H-pyran-2-one $\left(5 ; 3.5 \mathrm{mg}, t_{\mathrm{R}} 39.0 \mathrm{~min}\right.$; same gradient as in purification of 1 ); $1^{\prime}, 2^{\prime}$-dihydroxy-4-methoxy-6-pentyl-2H-pyran-2-one $\left(6 ; 1.2 \mathrm{mg}, t_{\mathrm{R}}\right.$ $20.3 \mathrm{~min}$; same gradient as in purification of 1$)$. Optical rotations were measured on a PerkinElmer 241 polarimeter (PerkinElmer, Lodz, Poland) and UV data were recorded on Shimadzu Biospec-1601 spectrophotometer (Shimadzu, Kyoto, Japan). IR data were recorded using a Nicolet Magna-IR 750 spectrophotometer (Nicolet Company, Madison, WI, USA). ${ }^{1} \mathrm{H}$ and ${ }^{13} \mathrm{C}$ NMR data were acquired with Varian Mercury-400, -500 and -600 spectrometers using solvent

\footnotetext{
${ }^{1}$ Institute of Medicinal Plant Development, Beijing, People's Republic of China; ${ }^{2}$ State Key Laboratory of Bioactive Substance and Function of Natural Medicines, Institute of Materia Medica, Chinese Academy of Medical Sciences and Peking Union Medical College, Beijing, People's Republic of China; ${ }^{3}$ Nanjing University of Information Science and Technology, Nanjing, People's Republic of China; ${ }^{4}$ Institute of Microbiology, Beijing, People's Republic of China and 5 Wuhan Institute of Virology, Wuhan, People's Republic of China

Correspondence: Professor G Ding, Key Laboratory of Bioactive Substances and Resources Utilization of Chinese Herbal Medicine, Ministry of Education, Institute of Medicinal Plant Development, Chinese Academy of Medical Sciences and Peking Union Medical College, Beijing 100193, People's Republic of China. E-mail: dgfyhchina@163.com
}

Received 30 October 2011; revised 15 February 2012; accepted 16 February 2012; published online 14 March 2012 
signals $\left(\mathrm{CDCl}_{3} ; \delta_{\mathrm{H}} 7.26 / \delta_{\mathrm{C}} 77.6\right)$ as references. The HMQC and HMBC experiments were optimized for 145.0 and $8.0 \mathrm{~Hz}$, respectively. ESIMS data were recorded on a Bruker Esquire $3000^{\text {plus }}$ spectrometer. HRESIMS and EIMS data were obtained using a Bruker APEX III 7.0 T spectrometer and APEXII FT-ICR (Bruker, Billerica, MA, USA), respectively.

The IR spectrum of $\mathbf{1}$ displayed hydroxyl group absorption at $3431 \mathrm{~cm}^{-1}$ (br.s) and carbonyl group signals at $1703 \mathrm{~cm}^{-1}$ (br.s). The molecular formula of photipyrone B (2) was determined to be $\mathrm{C}_{11} \mathrm{H}_{18} \mathrm{O}_{5}$ by analysis of its HRESIMS $\left(m / z 253.1040[\mathrm{M}+\mathrm{Na}]^{+}\right.$, $\Delta+0.6$ ), which was consistent with the NMR spectra data (Table 1 and Supplementary Figures S1 and S2). Detailed analysis of the ${ }^{1} \mathrm{H}$ and ${ }^{13} \mathrm{C}$ NMR data of 2 revealed the presence of structural features similar to those found in the known compound LL-P880 $\alpha(1),{ }^{12}$ except that the methylene unit (C-3) was disappeared, and an additional signal for one oxymethine proton with chemical shift value at $\delta_{\mathrm{H}} 4.12$ p.p.m. was observed, which implied that a methylene unit is replaced by an oximethine group. And this suggestion was also supported by the presence of one more oxygenate carbon in the ${ }^{13} \mathrm{C}$ NMR spectra of $2\left(\delta_{\mathrm{C}} 67.1\right)$. Finally, the structure was confirmed by ${ }^{1} \mathrm{H}-{ }^{1} \mathrm{H}$ COSY and $\mathrm{HMBC}$ correlations (Figure 1). ${ }^{1} \mathrm{H}-{ }^{1} \mathrm{H}$ COSY correlation revealed one isolated fragment corresponding to $\mathrm{C}-3-\mathrm{C}$ 2-C-7-C-8-C-9-C-10-C-11. The HMBC correlations from $\mathrm{H}-2$ to C-6, from $\mathrm{H}-3$ to $\mathrm{C}-4$ and $\mathrm{C}-5$ together with from $\mathrm{H}-5$ to $\mathrm{C}-3, \mathrm{C}-4$ and $\mathrm{C}-6$ established one $\alpha, \beta$-unsaturated $\gamma$-lactone moiety. The distinct cross peak from 12-OMe to C-4 in HMBC spectra placed the oxymethyl group attached at $\mathrm{C}-4$. The correlations from $\mathrm{CH}_{3}-11$ to C-9 and C-10, and that from $\mathrm{H}_{2}-10$ to $\mathrm{C}-8$ and from $\mathrm{H}-7$ to C-9 confirmed the connectivity of C-7-C-8-C-9-C-10-C-11 determined by ${ }^{1} \mathrm{H}-{ }^{1} \mathrm{H}$ COSY correlation (Figure 1). Thus the planar structure for 2 was determined. The relative configuration was determined by analysis of ${ }^{1} \mathrm{H}$ NMR $J$-values. The small coupling constant $(J \approx 0 \mathrm{~Hz})$ observed between $\mathrm{H}-2$ and $\mathrm{H}-3$ indicated that both protons were cis to each other with respect to the corresponding six-membered ring. ${ }^{19}$ The absolute configurations of C-2 and C-7 in 2 were postulated to be the same as those found in $\mathbf{1}$ on accounting for the similar biogenetic source as those of analogues.

Photipyrone C (3) was assigned the molecular formula of $\mathrm{C}_{11} \mathrm{H}_{18} \mathrm{O}_{5}$ (three degrees of unsaturation) on the basis of HRESI analysis $\left(m / z 253.1043[\mathrm{M}+\mathrm{Na}]^{+}, \Delta+0.3\right)$ and NMR data (Table 1 and Supplementary Figures S3 and S4). Comparison of the NMR spectra with those of $\mathbf{1}$ displayed the structural similarity, except that<smiles>[R]C1C(OC)=CC(=O)O[C@H]1[C@H](O)CCCI</smiles>

$1 \mathrm{R}=\mathrm{H}$

$2 \mathrm{R}=\mathrm{OH}$<smiles>CCCCC(O)C1OC(=O)C=C(OC)C1O</smiles>

cosy<smiles>[R]C(CC)C([R])[C@H](O)[C@H]1CC(OC)=CC(=O)O1</smiles>

$3 \mathrm{R}_{1}=\mathrm{H}, \mathrm{R}_{2}=\mathrm{OH}$

$4 \mathrm{R}_{1}=\mathrm{OH}, \mathrm{R}_{2}=\mathrm{H}$

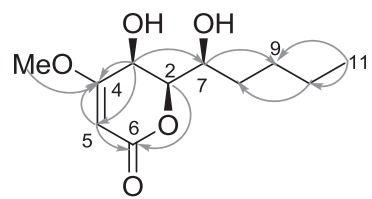<smiles>[R]C(CCC)[C@H](O)c1cc(OC)cc(=O)o1</smiles>

$5 \mathbf{R}=\mathbf{H}$

$6 \mathrm{R}=\mathrm{OH}$

Figure 1 Structures for compounds $1-6,1 \mathrm{H}-1 \mathrm{H}$ COSY, and Key HMBC for compound 2. A full color version of this figure is available at The Journal of Antibiotics journal online.

Table 1 NMR spectroscopic data for Photipyrone B (2) and Photipyrone $\mathrm{C}(3)$ in $\mathrm{CDCl}_{3}$

\begin{tabular}{|c|c|c|c|c|c|}
\hline \multirow[b]{2}{*}{ Position } & \multicolumn{3}{|c|}{ Photipyrone B (2) } & \multicolumn{2}{|c|}{ Photipyrone C (3) } \\
\hline & $\delta_{H^{a}}(J$ in $H z)$ & $\delta_{C}{ }^{\mathrm{b}}$, mult. & $H M B C(H \rightarrow C \#)$ & $\delta_{H^{a}}(\mathrm{~J}$ in $H z)$ & $\delta_{C}{ }^{\mathrm{b}}$, mult. \\
\hline 2 & 4.20 (br. s) & $80.1, \mathrm{CH}$ & $\mathrm{C}-3, \mathrm{C}-7$ & 4.38 , dt $(4.4,13)$ & $78.1, \mathrm{CH}$ \\
\hline 3 & 4.12 (br. s) & $67.1, \mathrm{CH}$ & $C-2, C-4, C-5$ & $\begin{array}{l}2.73, \text { ddd }(1.3,13,17) \\
2.30, \text { dd }(3.7,17)\end{array}$ & $37.5, \mathrm{CH}_{2}$ \\
\hline 4 & & 172.6, qC & & & 173.1, qC \\
\hline 5 & $5.18(\mathrm{~s})$ & $91.4, \mathrm{CH}$ & $\mathrm{C}-3, \mathrm{C}-4, \mathrm{C}-6$ & $5.14, \mathrm{~d}(1.3)$ & $90.1, \mathrm{CH}$ \\
\hline 6 & & $166.6, \mathrm{qC}$ & & & 166.6, qC \\
\hline 7 & $4.10(\mathrm{~m})$ & 71.3, $\mathrm{CH}$ & C-2, C-3 & $3.99, \mathrm{~m}$ & 73.4, CH \\
\hline 8 & $\begin{array}{l}1.65(\mathrm{~m}) \\
1.50(\mathrm{~m})\end{array}$ & $32.6, \mathrm{CH}_{2}$ & C-2, C-7, C-9, C-10 & $1.70, \mathrm{~m}$ & $30.8, \mathrm{CH}_{2}$ \\
\hline 9 & $1.65(\mathrm{~m})$ & $27.5, \mathrm{CH}_{2}$ & C-7, C-8, C-10, 11-Me & $3.85, \mathrm{~m}$ & $72.8, \mathrm{CH}$ \\
\hline 10 & $1.35(\mathrm{~m})$ & 22.7, $\mathrm{CH}_{2}$ & $\mathrm{C}-8, \mathrm{C}-9,11-\mathrm{Me}$ & $1.54, \mathrm{~m}$ & $28.8, \mathrm{CH}_{2}$ \\
\hline 11 & $0.92 \mathrm{t}(7.0)$ & $14.2, \mathrm{CH}_{2}$ & C-9, C-10 & $0.96, \mathrm{t}(7.6)$ & $9.6, \mathrm{CH}_{3}$ \\
\hline 12-OMe & $3.80(\mathrm{~s})$ & $56.7, \mathrm{CH}_{3}$ & C-4 & $3.76, \mathrm{~s}$ & $56.2, \mathrm{CH}_{3}$ \\
\hline
\end{tabular}


the methylene unit of C-9 was oxygenated to be one oxymethine group. And this observation was confirmed by the ${ }^{1} \mathrm{H}-{ }^{1} \mathrm{H}$ COSY correlations of $\mathrm{H}-9$ with $\mathrm{H}_{2}-8$ and $\mathrm{H}_{2}-10$, which determined the planar structure of 3. Analysis of coupling stands and comparison of the chemical shift values of C-2 and C-7 implied that both carbons in 3 might possess the same absolute configurations at C-2 and C-7 as those found in $\mathbf{1}$ and $\mathbf{4}$.

Secondary metabolites 1-6 were evaluated bioactivities against the human tumor cell line MDA-MB-231. And only compound 3 showed modest inhibitory effects on the growth of MDA-MB-231 with inhibitory rate at $25.0 \%$ and $23.0 \%$, respectively, when tested at $10 \mu \mathrm{g} \mathrm{ml}^{-1}$.

Photipyrones A (2) and B (3) are new $\alpha$-Pyrone analogues, members of a general class that is commonly found among different fungi and plants. $^{20-22}$ These two new compounds are the first secondary metabolites reported from Pestalotiopsis photiniae (L461), which builds up the hypothesis that endophytic fungi, as one kind of unique environmental microbes and relatively rare untouched reservoir, could be the potential sources for new/novel secondary metabolites as the potent lead compounds for agricultural and medicinal agents.

The structural family of compounds $\mathbf{1}-\mathbf{6}$ is completely different from that of photinides A-F isolated from the same fungus cultivated in SA media, ${ }^{5}$ which implied that Pestalotiopsis spp. might possess multiple different biosynthetic genes with huge biogenetic potential to produce diverse natural products, and variation of the easily accessible cultivation parameters, such as media composition, could trigger the expression of latent biosynthetic genes, which might influence directly or indirectly the transcription, translation, and enzyme activity/ specificity in the whole organism, ${ }^{1}$ and finally, lead to the produce of different secondary metabolites. Thus, the result from the present experiment promotes us to utilize Pestalotiopsis spp. fully to obtain more diverse and interesting bioactive secondary metabolites by using various fermentation media.

\section{ACKNOWLEDGEMENTS}

We gratefully acknowledge financial support from the National Natural Science Foundation of China (31000011), the Open Funding Project of the State Key Laboratory of Bioactive Substance and Function of Natural Medicines.
1 Bode, H. B., Bethe, B., Höfs, R. \& Zeeck, A. Big effects from small changes: possible ways to explore nature's chemical diversity. Chem. Bio. Chem 3, 619-627 (2002).

2 Ding, G. et al. Antifungal metabolites from the plant endophytic fungus Pestalotiopsis theae. J. Nat. Prod. 71, 615-618 (2008).

3 Ding, G. et al. Pestalazines and pestalamides, bioactive metabolites from the plant Fungus Pestalotiopsis sp. J. Nat. Prod. 71, 1861-1865 (2008).

4 Ding, G. et al. Ambuic Acid and Torreyanic Acid Derivatives from the Endolichenic Fungus Pestalotiopsis sp. J. Nat. Prod 72, 182-186 (2009).

5 Ding, G. et al. Photinides A-F, cytotoxic benzofuranone-derived $\gamma$-lactones from the plant dndophytic fungus Pestalotiopsis photiniae. J. Nat. Prod. 72, 942-945 (2009).

6 Ding, G. et al. Pestaloquinols $A$ and B, isoprenylated epoxyquinols from Pestalotiopsis spJ. Nat. Prod. 74, 286-291 (2011).

7 Liu, L. et al. Chloropupukenananin, the first chlorinated pupukeanane derivative and its precursors from Pestalotiopsis fici. Org. Lett. 10, 1397-1400 (2008).

8 Liu, L. et al. Pestaloficiols A-E, bioactive cyclopropane derivatives from the plant endophytic fungus Pestalotiopsis fici. Bioorg. Med. Chem. 16, 6021-6026 (2009).

9 Liu, L. et al. Isoprenylated chromone derivatives from the plant endophytic fungus Pestalotiopsis fici. J. Nat. Prod. 72, 1482-1486 (2009).

$10 \mathrm{Liu}, \mathrm{L}$. Pestalofones A-E, bioactive cyclohexanone derivatives from the plant endophytic fungus Pestalotiopsis fici. Bioorg. Med. Chem. 17, 606-613 (2009).

$11 \mathrm{Liu}, \mathrm{L}$. et al. Chloropestolide A, an antitumor metabolite with an unprecedented spiroketal skeleton from Pestalotiopsis fici. Org. Lett. 11, 2836-2839 (2009).

$12 \mathrm{Liu}$, L. et al. Unique metabolites of Pestalotiopsis fici suggest a biosynthetic hypothesis involving a Diels-Alder reaction and then mechanistic diversification. Chem. Comm. 46, 460-462 (2010).

$13 \mathrm{Liu}, \mathrm{L}$. et al. Chloropupukeanolides C-E, cytotoxic pupukeanane chlorides with a spiroketal skeleton from Pestalotiopsis fici. Chem. Eur. J. 17, 2604-2613 (2011).

$14 \mathrm{Li}$, E. et al. Pestalachlorides A-C, antifungal metabolites from the plant endophytic fungus Pestalotiopsis adusta. Bioorg. Med. Chem 16, 7894-7899 (2008).

$15 \mathrm{Li}$, E. et al. Pestalotheols A-D, bioactive metabolites from the plant endophytic fungus Pestalotiopsis theae. J. Nat. Prod. 71, 664-668 (2008).

16 Ellestad, G. A., Mcgahren, W. J. \& Kunstmann, M. P. Structure of a new fungal lactone, LL-P880 $\alpha$, from an unidentified Penicillium sp. J. Org. Chem. 37, 2045-2047 (1972).

17 Mcgahren, W. J., Ellestad, G. A., Morton, G. O. \& Kunstmann, M. P. A new fungal lactone, LL-P880 $\beta$, and a New Pyrone, LL-P880 $\gamma$, from a Penicillium sp. J. Org. Chem. 38, 3542-3544 (1973).

18 Ayer, W. A., Trifonov, L. S., Hutchison, L. J. \& Chakravarty, P. Metabolites from a woodinhabiting cup fungus, Urnula craterium. Nat. Prod. Lett. 14, 405-410 (2000).

19 Boalino, D. M. et al. a-pyrones and a $2(5 H)$-furanone from Hyptis pectinata. Phytochemistry 64, 1303-1307 (2003).

20 Kong, F., Singh, M. P. \& Carter, G. T. Pseudopyronines A and B, $\alpha$-pyrones produced by a marine Pseudomonas sp. F92S91, and evidence for the conversion of 4-hydroxy- $\alpha$ pyrone to 3-furanone. J. Nat. Prod. 68, 920-823 (2005).

21 Appendino, G. et al. Arzanol, an Anti-inflammatory and Anti-HIV-1 Phloroglucinol $\alpha$ Pyrone from Helichrysum italicum ssp. Microphyllum. J. Nat. Prod. 70, 608-612 (2007).

22 Dumontet, V. et al. Cytotoxic flavonoids and $\alpha$-pyrones from Cryptocarya obovata J. Nat. Prod. 67, 858-862 (2004).

Supplementary Information accompanies the paper on The Journal of Antibiotics website (http://www.nature.com/ja) 